\title{
Universal and Idioethnic Characteristics of Proverbs and Sayings with Zoonyms in the English and Kazakh Languages
}

\author{
Shara Mazhitayeva ${ }^{1}$, Zhanar Omasheva ${ }^{2}$, Akerke Tazhikeyeva $^{1}$, Zhanbai Kadyrov ${ }^{3}$, Zhanar Talaspayeva ${ }^{3}$ \& \\ Saniya Otynshina ${ }^{1}$ \\ ${ }^{1}$ Karaganda State University named after Academician E. A. Buketov, Kazakhstan \\ ${ }^{2}$ Karaganda State Medical University, Kazakhstan \\ ${ }^{3}$ North Kazakhstan State University named after Manash Kozybayev, Petropavlovsk \\ Correspondence: Shara Mazhitayeva; Mukanov street 1-8, Karaganda, 100026, Kazakhstan. E-mail: \\ S_mazhit@mail.ru; sh-mazhit@inbox.ru
}

$\begin{array}{lcc}\text { Received: February 28, } 2015 & \text { Accepted: March 20, } 2015 \quad \text { Online Published: April 24, } 2015 \\ \text { doi:10.5539/res.v7n6p178 } & \text { URL: http://dx.doi.org/10.5539/res.v7n6p178 }\end{array}$

\begin{abstract}
The article is devoted to the universal and idioethnic characteristics of proverbs and sayings with zoonyms in the English and Kazakh languages. Applying comparative, statistical and component methods in the analysis of lexical structure of more than 2 thousand proverbs and sayings, the authors identified universal and idioethnic characteristics inherent in each of the ethnic groups, correlation of the images of zoonyms in proverbs and sayings of the English and Kazakh languages.
\end{abstract}

Keywords: ethnolinguistics, zoonym, image, proverbs and sayings with zoonyms in the English and Kazakh languages

\section{Introduction}

Relationship and interaction of language and culture is one of the key problems in modern linguistics, because "in most cases, a person does not deal with the world itself, but with its representations, with cognitive patterns and models. A person imagines the world (or different worlds) through the prism of its culture and language in particular being an integral part of the culture" Makovskiy (1996), Jackendoff (1983) and Lakoff (1987) write about language embodiment occurring due to cognitive processes and mechanisms.

As the most important function of culture is the accumulation and processing of information received in the course of human activity, then culture is directly related to the peculiarities of national mentality. "Mentality is a view of the world outlook in the categories and forms of native language that connects the intellectual, spiritual and permissive qualities of national character in its typical manifestations. Language embodies the national character, national idea and national ideals, which in their finished form can be represented in the traditional symbols of the given culture" (Kolesov, 1992).

Interaction of language and culture is studied by such disciplines as cultural linguistics, ethnolinguistics, ethnopsycholinguistics. In defining the term "ethnolinguistics" we adhere to the viewpoint of N. I. Tolstoy, who considers ethnolinguistics as an interdisciplinary direction, studying language and culture in integrity.

Not just a reflection of folk culture, psychology, and mythological concepts in language, but the constructive role of language and its influence on the formation and functioning of folk culture, folk psychology and folk creative activity is of great concern for ethnolinguistics.

Different aspects of ethnolinguistics are studied in the works of Russian scholars. Nikitina (1993), Tolstoy (1997), Teliya (1999), Bartminskiy (2005), Tolstaya (2010) and etc.

Ethnolinguistic school in Kazakhstan is connected with the name of an academician A. T. Kaidarov considering the history of the Kazakh ethnos, reflection of life in modern objective reality within language (Kaidarov, 2006).

The above mentioned aspects were studied by a large group of Kazakh scholars such as Gabitkhanuly (2006), Karsybekova (2004), Zhusupova (2004), Atakhanova (2005), Atabayeva (2006), Katykbayeva (2007), Mankeyeva (2008), Mazhitayeva and Tazhikeyeva (2012), etc. 


\section{Materials and Methods}

The basic material for the study consists of more than 2 thousand phraseological comparisons, proverbs and sayings. Card index is compiled on the basis of phraseological, paremiological dictionaries of the English and Kazakh languages. Scientific works of ethnolinguistic and linguistic-cultural character of foreign, Russian and Kazakh scholars, considering issues of language and thought, language, culture and ethnicity, the point of view of prominent scholars regarding the language as a bunch of cultural information (Jackendoff, Lakoff, Tolstoy, Teliya, Kaidarov, Mankeyeva, Atabayeva, \& Issina, etc.), and reflection of this information in English and Kazakh proverbs and sayings (Kunin, Speake, Ridout, Albov, Rakhmetova, Keikin, \& Smailova) became the methodological basis of our work. The main research methods are descriptive, comparative, statistical and componential analyses.

\section{Results}

In the result of the continuous sampling of the studied material we revealed proverbs and sayings containing similar zoormorphic images and vica versa not coinciding in another language. Correlation of the images of zoonyms in the proverbs and sayings of the English and Kazakh languages is presented in the following table

Table 1. Correlation of the images of zoonyms in the proverbs and sayings of the English and Kazakh languages

\begin{tabular}{|c|c|c|}
\hline zoonym naming unit & $\begin{array}{l}\text { number of proverbs and sayings in } \\
\text { English (in \%) }\end{array}$ & $\begin{array}{l}\text { number of proverbs and sayings } \\
\text { in the Kazakh language (in \%) }\end{array}$ \\
\hline Dog & $36(24,5)$ & $150(19,8)$ \\
\hline hack / horse / mare / & $25(16,1)$ & $174(22,9)$ \\
\hline male cat/ female cat & $19(12,9)$ & $4(0,5)$ \\
\hline cow / bull & $13(8,8)$ & $34(4,5)$ \\
\hline Ox & $1(0,7)$ & $11(1,4)$ \\
\hline sheep / ram & $10(4,1)$ & $57(7,5)$ \\
\hline Fox & $6(4,1)$ & $20(2,6)$ \\
\hline ass & $6(4,1)$ & $34(4,5)$ \\
\hline Pig & $10(4,1)$ & $5(0,6)$ \\
\hline Bear & $3(2,0)$ & $2(0,3)$ \\
\hline Wolf & $7(4,8)$ & $30(4)$ \\
\hline Hare & $4(2,7)$ & $11(1,4)$ \\
\hline Mouse & $5(3,4)$ & $7(0,9)$ \\
\hline Mole & $1(0,7)$ & - \\
\hline
\end{tabular}




\begin{tabular}{lll}
\hline Leopard & $1(0,7)$ & - \\
Monkey & $2(1,4)$ & - \\
Camel & $1(0,7)$ & $170(22,4)$ \\
Lion & $3(2,0)$ & $15(2)$ \\
female goat/male goat & - & $7(0,9)$ \\
Kulan & - & $17(2,2)$ \\
arkhar (wild sheep) & - & $1(0,1)$ \\
Saiga & - & $6(0,8)$ \\
Badger & - & $2(0,3)$ \\
groundhog & & $1(0,1)$ \\
Elk & & $2(0,3)$ \\
Elephant & & $1(0,1)$ \\
\hline
\end{tabular}

The greatest number of proverbs and sayings in both languages are the ones containing lexical units "dog", "horse", "cow / bull". Meanings they represent can be seen on the example of the following schemes: 


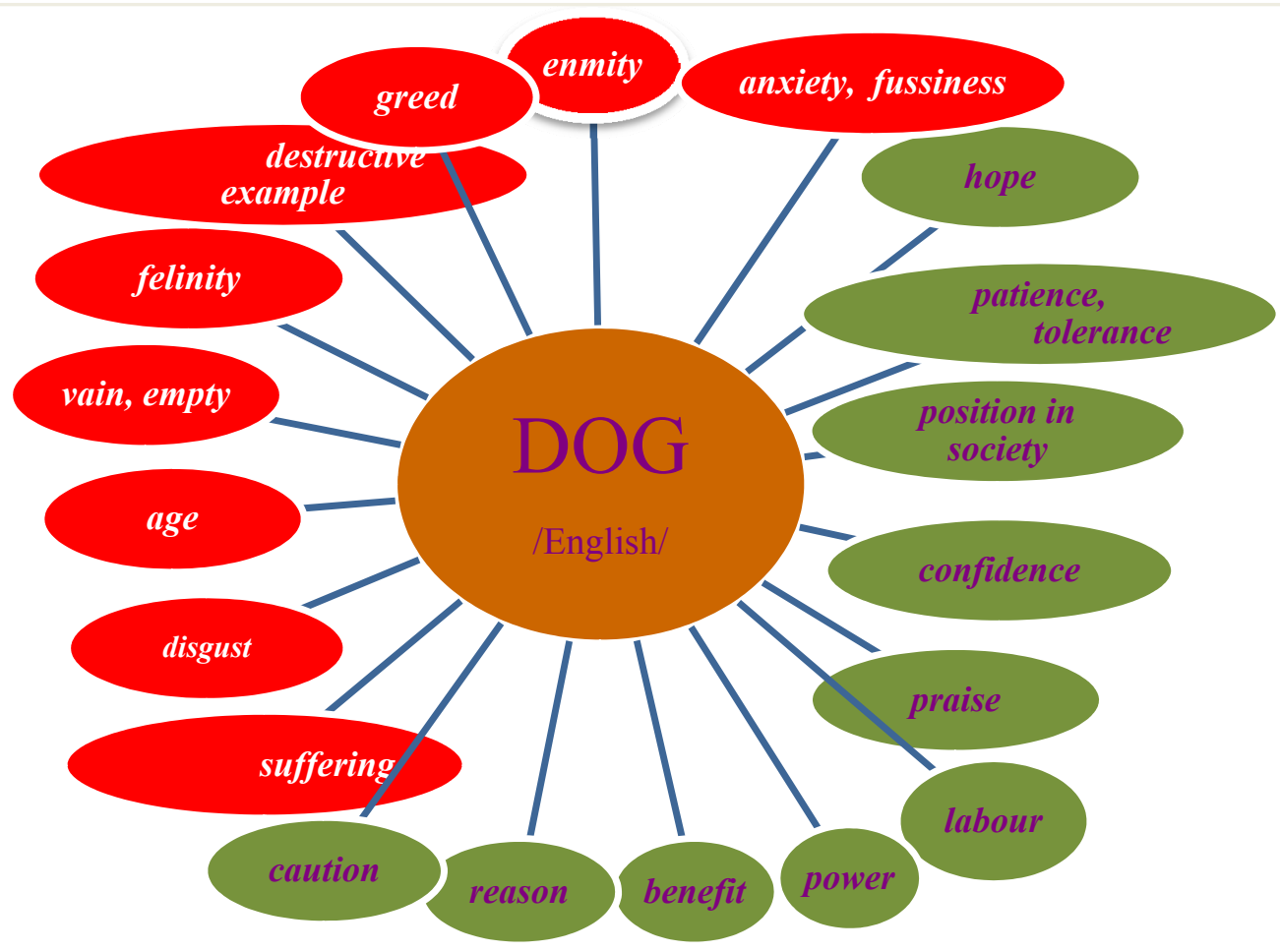

Figure 1. Meaning of the lexical unit "dog" in the English language

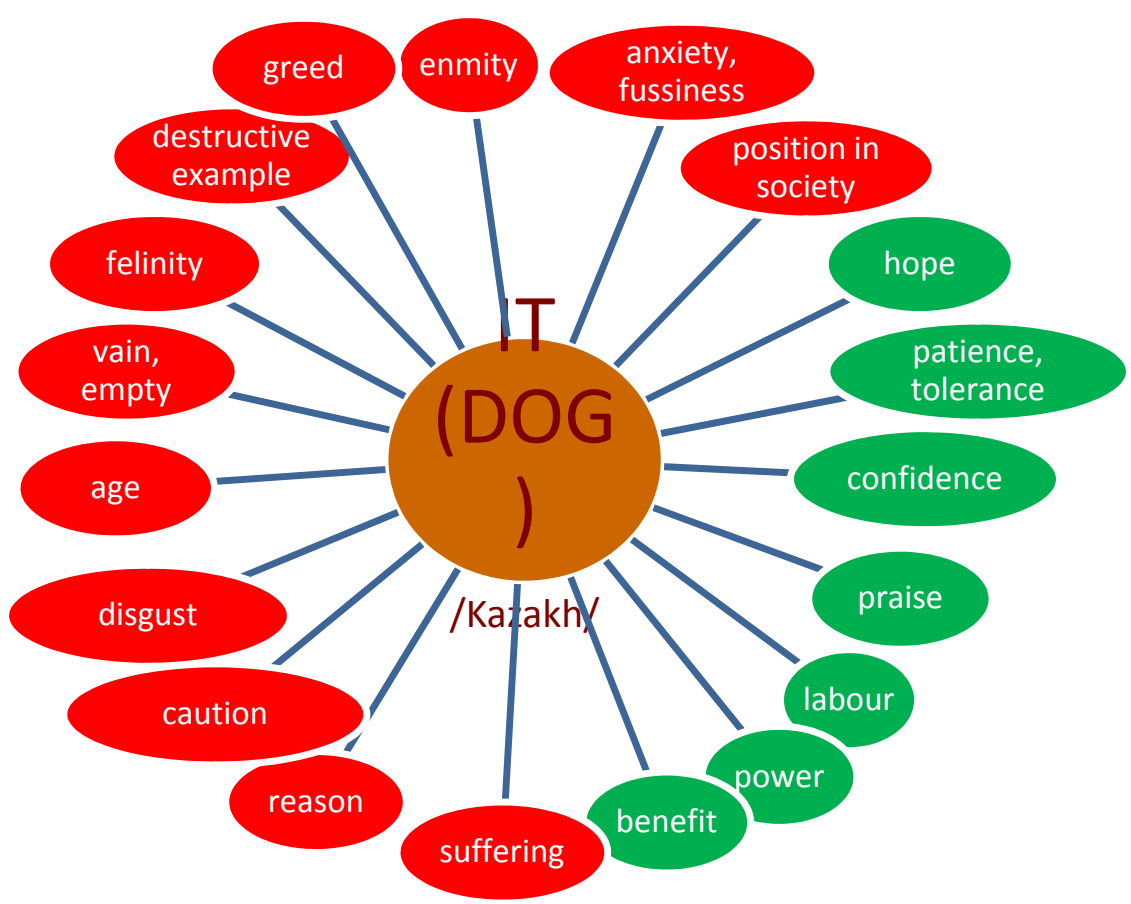

Figure 2. Meaning of the lexical unit "it" (dog) in the Kazakh language

\section{Discussion}

We can distinguish two groups within a general layer of proverbs and sayings of the English and Kazakh languages. Units of the first group transfer general universal meanings by means of the same zoomorphic images. The second group is units representing specificity by means of zoomorphic images. Negative and positive 
evaluation in combinations with live internal form is usually closely associated with negative and positive images embodied in these proverbs and sayings, and based on the literal meaning of their components.

Contrastive-comparative analysis of proverbs and sayings of the English and Kazakh languages showed that similar images can function within cultural diversity. According to the results of our study proverbs and sayings with the component "dog" in the English are used to express and describe different conceptual categories (for example, in the English: "vain, empty", "The dog barks, but the caravan goes on" (Jennifer Speake. Oxford dictionary of proverbs, 2002); in the Kazakh language "It uredi, Keruen koshedi" (word for word translation: The dog barks, but the caravan moves) (Keikin, 2002, Proverbs and sayings of the Kazakh people). We also can see it in "a sense of homeland, native land"-Every dog is a lion at home (dictionary of the English proverbs); "Oz koshesinde it te zholbaris" (word for word translation: Even a dog feels itself a tiger in its home street) (Keikin, 2002, Proverbs and sayings of the Kazakh people).

"Stupidity", "arrogance" is expressed by means of the image of an ass: Jest with an ass and he will flap you in the face with his tail (Russian-English-Latin dictionary of proverbial expressions, 2006); in Kazakh "Esekti sipasan, tuzge karai angiraidi" (word for word translation: Pet the ass, but he still yells towards outside) (Keikin, 2002); An ass in a lion's skin (Kunin, 1984); in Kazakh "Esek semirse, iyesin teber" (word for word translation: A fat ass, kicks its master) (Keikin, 2002).

Image of the horse possesses a positive quality: Never spur a willing horse (Russian-English-Latin dictionary of proverbial expressions); in Kazakh "Kazanat at kamshy saldyrmaydy" (word for word translation: An obedient horse does not need a whip (Keikin, 2002); A ragged colt may make a good horse (Ridout \& Witting, 1997). Tulpar-kulynnan. Batyr-baladan (word for word translation: A foal will become a horse and the child will grow a hero (batyr))" (Keikin, 2002).

"Strength, courage," is connected with the image of the lion: To beard the lion in his den (Kunin, 1984); in the Kazakh language "Arystandy arystandai zhigit alar (word for word translation: Lion can be defeated by a man with a lion's spirit (Keikin, 2002).

The image of the fox expresses "cunning": When the fox preaches, take care of your geese (Kunin, 1984); in the Kazakh language: "Ailali tulki aldyrmas" (word for word translation: An artful fox can't be caught by the tail) (Kazakh proverbs and sayings). Humility, meekness is attributed to a sheep (lamb): March comes in like a lion and goes out like a lamb. (Kunin, 1984). In the Kazakh language "Koi auzynan shop almas"( word for word translation: Will not even take a grass-blade from the sheep's mouth) (Keikin, 2002. Kazakh proverbs and sayings).

"Cowardice" is associated with the hare: Hares may pull dead lions by the beard (Russian-English-Latin dictionary of proverbial expressions); in the Kazakh language "Koyan oz kolenkesinen korkady" (word for word translation: Hare is afraid of its own shadow) (Keikin, 2002).

"Self-confidence" is expressed through the image of a mouse: It's a bold mouse that nestles in the cat's ear (Russian-English-Latin dictionary of proverbial expressions). In the Kazakh language "Oleyin degen tyshkan mysyktyn kuirigimen oinaidy" (word for word translation: Mouse, which seeks death, plays with the cat's tail) (Keikin, 2002).

"Felinity, hypocrisy" is represented by the image of a wolf: $A$ wolf in sheep's clothing (English-Russian phraseological dictionary); Meanings coincide in the Kazakh language "Koi terisin zhamylgan bori (word for word translation: A wolf covering itself with the lambskin" (Keikin, 2002). As observed from the above examples, the form of expression and use of such units is similar in both languages. This allows us to suggest that the cause of similar meanings of analogous zoonyms actually observed in some cases of languages with different structures can be either existence of general sources of image or borrowing.

This speaks for the historical commonness of cultures or their interactions in a certain period of time. G. I. Issina explains the variety of national images due to the fact that the most of phraseological units have free and temporary word combinations as the basis of its formation reflecting in its semantics subjects, phenomena, situations, circumstances of that objective reality, where one or another nation lives (Issina, 2005, 2012).

A large group of proverbs and sayings occurs in the English and Kazakh languages in the content of which zoomorphic images reflect the specificity of the ethnically oriented cultural constants that exist in the minds attributing to the animals humane qualities and characteristics.

For example, the following proverb "The death of wives and the life of sheep make her husband rich" contains information about medieval England, when the process of marriage depended on the will of parents. In order to improve material conditions parents looked for a groom or bride from a wealthy family, with a position and title. 
Specific properties of proverbs and sayings can be seen also in the absence of some zoomorphic images in English proverbs such as: female goat/ male goat, tiger, wild boar, saiga, wild ass (kulan), badger, wild sheep, elk, marmot, an elephant. This is explained by the fact that each nation uses its own culture-specific concepts.

Thus, the historical evidence suggests that fur of animals was valued in the steppe as the traditional material of the Kazakh national costume. Fur of onagers, saiga and tigers, as well as raccoon, sable, marten and ferret fur were highly valued. Coats were sewn from fur. Accordingly clothing from the fur of a racoon was called zhanat, furcoat from Manichaean fox was called kara tulki ton (black fox coat), bota ton-a furcoat from camel's fur, kamshat borik was beaver (beauxite). Long hairs had been pulled out of goat fur, leaving the undercoat. Fur coats from such fur was called kylka zhargak. Fur coats had been covered with silk and other fabrics, brought in by merchants from India, China and Central Asia. So the exchange trade developed on the ancient caravan Silk Road passing through the cities of Southern Kazakhstan. Specific characteristics were also noted in proverbs and sayings with the lexical unit "tuye" (camel) which represent a large number of representations that is explained by the conditions of habitat of that animal.

Camels are found in arid areas of Central and Southern Kazakhstan, on the shores of Balkhash Lake, in the valley of the Chu River. We distinguished one English proverb with the mentioned lexical unit, since the conditions and climate differ from Kazakhstan. Specific characteristics of proverbs, in our opinion, can also be observed in the explicitation of age of the Kazakh pets (at/horse, siyir/cow, tuye/camel, koi/sheep) and products made from meat and milk.So, a smoked meat of the horse beef is called kazy, a speciality of Kazakhs, the varieties of which include zhylt kazy, shynashak kazy, barmak kazy, bir eli kazy, kos kazy, taban kazy, ulpa kazy, ala bult kazy and etc. Kumis is made of mare's milk, which also has several types: tunemel kymyz (one day stand), kunan kymyz (two days stand), donen kymyz "(three-days stand), besti kymyz (four-days stand)". Englishmen prepare yogurt from cow's milk, cake, popovers, kuchen, bun. Flywhisks, ropes are made of cow's tail.

\section{Conclusion}

At the heart of a large number of proverbs and sayings of the English and Kazakh languages there is metaphorical reinterpretation of the linguistic form that is caused by a large number of motivational signs. The same image comes out in a variety of proverbs and sayings in the English and Kazakh languages expressing any human qualities or points to a generalized concept. Generalization is often given in the form of conclusions about life and everyday or moral recommendations. Based on empirical data, using cluster analysis as a methodological instrument, we proposed a detailed classification of paremiological units including zoonyms. A detailed classification includes the following names: Moral qualities, emotional and mental states, work, social and physical characteristics, mental ability, moral and ethical views. Thus, recognition of the homeland, native land in the English proverbs is transmitted by means of using lexical unit "dog", "cock", in the Kazakh language through lexical units "it" (dog), "kortishkan" (mole), "at" (horse). The following qualities of a person as silence, greed, arrogance, felinity and hypocrisy, cunning, deceit, anxiety, fuss, cowardice, vain are perceived negatively in both cultures while courage, determination, caution are considered to be positive qualities.

Along with the similarity of views on these human qualities, we can notice some differences as well. Thus, there is no such a lexical unit as "curiosity" in the Kazakh language, but it occurs in the English language which implies that non-intervention in other people's lives is a social norm for English people. Private life for English people is a response to overcrowding, the desire to protect the personal space that they jealously guard. Proverbs containing lexical unit "care" demonstrate restraint in manners as anxiety and excessive concern will not lead to something good.

In the Kazakh national identity lexical unit "care" means care for the cattle, knowledge of good conditions for grazing. Work, skills and knowledge are valued in both languages, whereas laziness, idleness evoke scorn. We noted a sufficient number of the English proverbs in this subgroup, criticizing useless and unnecessary work, compared with proverbs of the Kazakh language. English ethnic group identifies the following names of animals within social inequality group that characterizes common man $(\mathrm{dog})$ and belonging to a privileged section of society (lion, horse).

Social inequality is not expressed sharply in Kazakh proverbs, as there is an opposition buzau (calf) - ogiz (ox). Lower evaluation is inherent in family and kinship relations in the English outlook, expressing one's attitude through the use of lexical units blacksheep, badcalf. Friendship, integrity, emergence of descendants are valued within family relations of the Kazakh people. In the understanding of the Kazakh people loneliness is considered a bad sign. Moral and ethical perception (praise, ingratitude, bragging, modesty, resignation) were mentioned in both languages, however the degree of their expressiveness varies. For example, English people associate praise 
with the dog, while Kazakh people with a dog, a sheep, a horse. Doing the work for someone or showing respect to the people who do not deserve a good treatment is considered as ingratitude for English and expressed through lexical units $d o g$, pig.

The Kazakhs compare ingratitude with the $d o g$ that rushes to the master, with a fat ass and cow not appreciating affection. Boasting in English and Kazakh outlook causes negative emotions. This quality demonstrates the pragmatic view of the ethnic group in English proverbs, therefore there are expressions like catch the . before ; wait for. Humility, resignation are mentioned by both ethnic groups, so similar lexical units lamb, koi occur. In addition to the lexical unit koi (sheep) in Kazakh proverbs we have lexical unit tuye (camel). In order to describe intellectual abilities which due to their presence or absence possess positive or negative connotations such zoomorphic images are used in English: old fox, old ox, old dog, ass, sheep; in the Kazakh language zhaksy at (good horse), tuye (camel), esek (ass), zhaman koi (bad sheep), teke (goat), zhaksy it (good dog), zhaman it (bad dog).

Physical description for both cultures includes a description of age (old/young), strength and health. So, old age is compared with the lapse, the loss of health: old dog, old ape, and kari at (old horse) kari siyir (old cow), kari arystan (old lion), kari kaskyr (old wolf). Youth is correlated with the deeds and actions of old people: old cowa calf, old cock-young, siyir (cow)—buzau (calf), kari koy (old sheep)—zhas koi (young sheep).

Strength, endurance in English is shown by means of such images as lion, horse, camel, wolf, in the Kazakh it is represented by lexical units tuye (camel), koshkar (tupping ram), it (dog), kaskyr (wolf). Denotation of the lexical unit "health" in the English language is actualized in the meaning of "all is healed in vivo" by means of the denotations cat, nine lives. It has different meaning in the Kazakh language and implies that "disease will dump anyone" through denotations of lexical units auru-illness, atan-castrated camel, shoktirer-to be greatly reduced by illness. In proverbs of the thematic group "unreality, impossibility of dreams" we can see similarities of opinions expressed in criticizing actions and deeds that do not occur in reality. This group is characterized by lexical units "pigs", "wishes of horses" (If wishes were horses, beggars would ride), "cows", "a mare's nest" in English proverbs, and "eshki kuirigi" (goat's tail), "tuyening kuirigi" (the tail of a camel) in Kazakh.

Characteristics of human relationships, behaviors and actions are represented through the thematic group "behavior, deeds" which includes other lexical units as punishment, reprimand, risk and self-confidence. In both languages, human behavior in most cases possesses negative connotation, representing the images of $d o g$, $h o g$, chick, wolf, arystan (lion), tuye (camel), siyir (cow), tyshkan (mouse), eshki (goat), esek (ass), kunazhyn (heifer in milk), kaskyr (wolf) and only in a few cases positive characteristics are realized through the following lexical units as good dog, good horse, zhaksy at (good horse), zhaksy it (good dog), tuye (camel).

Presence of one and the same zoomorphic image in contrasted languages confirms similarity of thinking of ethnic groups: Do not spur a willing horse. Kazanat kamshy saldyrmaidy (word for word translation: An obedient horse does not need a whip). The mouse lordships where a cat is not. Mysyk zhokta tyshkan tobege shygady (word for word translation: When a cat is away mouse will climb one's head). The absence of certain zoomorphic images tells about updating the values of ethnic groups, therefore lexical units curse,risk are not correlated with zoomorphic images in the Kazakh language, while it is not peculiar for the English culture to restrict the rights of man, a person is regarded as an integral, independent, capable of taking risks. Negative attitude toward human nature and manifestation of the relationship between people are represented in proverbs through lexical units dog, wolf, cat, ass, zhaman at (bad horse), it (dog),kaskyr (wolf), esek (ass), kingir biye (stubborn mare), tyshkan (mouse), ayu (bear). In other cases, depending on the situation, zoomorphic images dog, wolf, it (dog), kaskyr (wolf) acquire positive connotation: Dog does not eat dog. Wolf never was against wolf. Aynalada yel bolmasa, it te zholdas (word for word translation: If there is no one around a dog makes friend). Kaskyr da kandasyna kastyk kylmaidy (word for word translation: Even a wolf will not stab its kin).

\section{References}

Atabayeva, A. (2008). Ethnolinguistic cognitive bases of the Kazakh dialectal lexicon (p. 356). Almaty.

Atakhanova, R. K. (2005). Ethnolinguistic features of proverbs and sayings of unrelated languages (based on German and Kazakh proverbs and sayings) (p. 34). Almaty.

Bartminskiy, Y. (2005). Linguistic image of the world: Essays on ethnolinguistics (p. 512). Moscow: Idrik.

Gabitkhanuly, K. (2006). Linguistic representation of the Kazakh mythology (p. 168). Almaty: Arys.

Issina, G. I. (2005). Phraseological comparisons within the system of English phraseology: Monograph (p. 178). Karagandy KarSU publishing house. 
Issina, I. G. (2012). Stereotypes and national language picture of the world. Monograph (p. 237). Karaganda.

Jackendoff, R. S. (1983). Semantics and cognition. Cambridge. Mass: MIT Press.

Jennifer, S. (2002). Oxford dictionary of Proverbs. Oxford university Press.

Kaidarov, A. T. (2008). Fundamentals of ethnolinguistics (p. 302). Almaty.

Karsybekova, Sh. P. (2004). Ethnolinguistic principles of the classification of proverbs and sayings in the Kazakh language (p. 163). Almaty.

Katykbayeva, M. B. (2007). Ethnolinguistic study of permanent comparisons in the English and Kazakh languages: abstract of PhD thesis (p. 24). Almaty.

Keikin, Zh. (2002). 7777 proverbs and sayings of the Kazakh people (p. 448). Almaty: Publishing house "Olke".

Kolesov, V. V. (1992). Concept of culture: Image-concept-symbol. Bulletin of St. Petersburg University, 3(16), 78-83.

Kunin, A. V. (1984). English-Russian phraseological dictionary (4th ed., revised and complemented, p. 944). Moscow: Russian Language.

Lakoff, G. (1987). Women, Fire and Dangerous Things: What Categories Reveal about the Mind. Chicago: University of Chicago Press.

Makovskiy, M. M. (1996). Comparative dictionary of mythological symbolic in Indo-European countries. Image of the world and myths of images (p. 415). Moscow: VLADOS.

Mankeyeva, Zh. (2008). Cognitive bases of ethnic and cultural namings in the Kazakh language (p. 238). Almaty.

Mazhitayeva, Sh., \& Tazhikeyeva, A. (2012). Gender Aspect in the Kazakh Language (Based on Proverbs and Sayings). European Researcher, 37(12-2), 2186-2190.

Nikitina, S. Y. (1993). Oral folk culture and language awareness. Moscow: Nauka.

Rakhmetova, M. K. (2007). Kazakh proverbs and sayings (p. 240). Almaty: Publishing house "Koshpendiler".

Ridout, R., \& Witting, C. (1997). Dictionary of the English proverbs (p. 104). St. Petersburg.

Russian-English-Latin dictionary of proverbial expressions (2006). Comp. A. S. Albov. M.: AST; St. Petersburg: Sova.

Teliya, V. N. (1999). Phraseology in the context of culture (p. 336). Moscow: Languages of Russian culture.

Tolstaya, S. M. (2010). Semantic categories of language and culture. Essays on the Slavic culture (p. 368). Moscow: Librokom.

Tolstoy, N. I. (1997). Ethnolinguistics among humanities (p. 315). Russian philology: An Anthology.

Zhusupova, I. (2004). Ethnolinguistic peculiarities of Kazakh and English proverbs and sayings: Abstract of PhD thesis (p. 25). Almaty.

\section{Copyrights}

Copyright for this article is retained by the author(s), with first publication rights granted to the journal.

This is an open-access article distributed under the terms and conditions of the Creative Commons Attribution license (http://creativecommons.org/licenses/by/3.0/). 